\title{
Impact of hand hygiene product accessibility on 5 moment compliance within an acute care facility ward
}

\author{
DP Limbert ${ }^{1 *}$, M Nabuurs-Franssen ${ }^{2}$, P Besselink-Quint ${ }^{3}$, F van den Wildenberg ${ }^{3}$, J Schaafstra ${ }^{4}$, J Hines ${ }^{1}$, A Voss $^{2}$ \\ From 3rd International Conference on Prevention and Infection Control (ICPIC 2015) \\ Geneva, Switzerland. 16-19 June 2015
}

\section{Introduction}

24/7 electronic monitoring of hand hygiene $(\mathrm{HH})$ product use enables the accurate assessment of $\mathrm{HH}$ compliance and behavioural patterns in a facility ward pre and post intervention. One such intervention being an increase in $\mathrm{HH}$ product accessibility.

\section{Objectives}

Assess the impact on $\mathrm{HH}$ behaviour of adding ABHR at point of patient care.

\section{Methods}

A group $\mathrm{HH}$ surveillance system was installed in a surgery ward such that all existing wall mounted Soap \& ABHR dispensers were monitored. Dispensers were located at the entrance to patient rooms and over the sinks within. Data was not made visible to the ward staff to ensure that behaviours were unaffected.

Following a baseline period of 70 days, portable 'pointof-care' ABHR dispensers were added at the end of the patient beds and the impact on $\mathrm{HH}$ compliance and dispenser usage patterns was assessed over a further 70 day intervention period.

\section{Results}

During the baseline period the average daily calculated compliance was $23 \%$ (compared to an average of $65 \%$ in the presence of an observer).

During the intervention period the average daily calculated compliance was $26 \%$

Analysis of the $13 \%$ increase in $\mathrm{HH}$ compliance revealed a reduction of $2 \%$ in $\mathrm{HH}$ events taking place in the hallway compared with an in-patient room increase of $34 \%$.

\section{Conclusion}

The work demonstrates that positive change in group behaviour can be affected by improved $\mathrm{HH}$ product access, with both an increase in overall $\mathrm{HH}$ compliance and a shift in the number of $\mathrm{HH}$ events taking place within the patient room, consistent with WHO 5 Moments teaching.

\section{Disclosure of interest}

None declared.

\section{Authors' details}

${ }^{1}$ Research \& Development, Deb Group Ltd, Denby, UK. ²Department of Medical Micriobiology and Infectious Diseases, Canisius-Wilhelmina Hospital, Netherlands. ${ }^{3}$ Department of Surgery, Canisius-Wilhelmina Hospital, Netherlands. ${ }^{4}$ Department of Urology, Canisius-Wilhelmina Hospital, Netherlands.

Published: 16 June 2015

\section{doi:10.1186/2047-2994-4-S1-P298}

Cite this article as: Limbert et al:: Impact of hand hygiene product accessibility on 5 moment compliance within an acute care facility ward. Antimicrobial Resistance and Infection Control 2015 4(Suppl 1):P298.

${ }^{1}$ Research \& Development, Deb Group Ltd, Denby, UK

Full list of author information is available at the end of the article 